\title{
Tenientes gobernadores del Alto Huallaga: entre el gobierno nacional y la comunidad rural 1
}

\author{
Artículos originales: SOCIOLOGÍA \\ Recibido: 20/09/2020 \\ Aprobado: 04/11/2020 \\ Publicado: 05/02/2021
}

\author{
Gonzalo Diego Falla Carrillo \\ Pontificia Universidad Católica del Perú \\ gfalla@pucp.edu.pe
}

\begin{abstract}
RESUMEN
El objetivo principal de esta investigación fue comprender la naturaleza y desempeño de los tenientes gobernadores como representantes del gobierno nacional y líderes locales en comunidades rurales de la zona del Alto Huallaga. La hipótesis de este estudio es que el proceso de designación de los tenientes gobernadores como autoridades políticas locales y la naturaleza de sus funciones, genera las condiciones para que el ejercicio de las tenencias de gobernación se desarrolle en función de las necesidades y prioridades de las comunidades, antes que como representación del gobierno. Se aplicó una metodología de investigación cualitativa a través de entrevistas en profundidad y el análisis de fuentes secundarias. De esta manera se ha analizado los significados que los tenientes gobernadores dan a sus experiencias como autoridades políticas en localidades rurales, relacionándolos con el marco normativo e institucional, la densidad estatal en el ámbito rural y el contexto del Alto Huallaga.
\end{abstract}

Palabras clave: Tenientes gobernadores; representación; comunidad; Alto Huallaga.

\section{Lieutenant Governors from Upper Huallaga: between national government and rural communities}

\begin{abstract}
The main objective of this research is to understand the nature and performance of lieutenant governors as representatives of the national government and local leaders in rural communities in the Upper Huallaga area. The hypothesis of this study is that the process of designation of the lieutenant governors as local political authorities and the nature of their functions generates the conditions for the exercise of the governance tenures to develop according to the needs and priorities of the communities, rather than as representation of the government. A qualitative research methodology was applied through in-depth interviews and analysis of secondary sources. In this way, the meanings that the lieutenant governors give to their experiences as political authorities in rural localities have been analyzed, relating them to the normative and institutional framework, the state density in rural areas, and the context of Upper Huallaga.
\end{abstract}

KEYwords: Lieutenant Governors; Representation; Community; Upper Huallaga.

1 El presente artículo procede de la tesis «Gobierno nacional y comunidades rurales bajo estado de emergencia: percepciones de tenientes gobernadores del Alto Huallaga», con cuya sustentación el autor obtuvo el grado de Magister en Sociología con mención en Estudios Políticos en la Universidad Nacional Mayor de San Marcos, el año 2018. 


\section{Introducción}

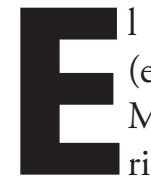
I territorio conocido como Alto Huallaga (entre los departamentos de Huánuco y San Martín), desde la década de 1930, fue escenario de un proceso complejo de colonización de la selva que puso mayor énfasis en la construcción de infraestructura productiva alrededor de la carretera Marginal, generando un notable crecimiento de la frontera agrícola, el cual, posteriormente en la década del 1970, dio lugar al auge del cultivo de coca orientado al narcotráfico (Aramburú, 1984: 67; Camino, 1984: 85-86; Lesevic, 1984: 27-29; Namuche, 1995). La respuesta del estado llegó en forma de declaración del estado de emergencia en 1978 para ejecutar operativos antinarcóticos de gran envergadura. Después, con la expansión de la subversión y la contrasubversión, durante las dos últimas décadas del siglo XX, la prioridad del Estado peruano fue establecer el control y la seguridad del territorio (Páucar, 2006). Así, el Alto Huallaga vivió bajo estado de emergencia entre 1984 y 2015 (con un intervalo entre 2001 y 2004), esto es, con un régimen de democracia restringida, dejando pendiente la tarea de desarrollar instituciones que garanticen en alguna medida la vigencia del estado de derecho y un nivel de funcionamiento aceptable de la administración pública.

Al término de la segunda década del siglo XXI, la cadena productiva de la droga sigue involucrando a un sector de la población, aunque en magnitudes significativamente menores que en años anteriores. En 2009, el Alto Huallaga era la cuenca cocalera con mayor extensión cultivada de coca en el país, con 17,497 hectáreas, mientras que en el 2017 se había reducido a sólo 1,623 hectáreas (Oficina de Naciones Unidas contra la Droga y el Delito, 2018). Asimismo, esta década también significó la desactivación de los grupos subversivos que operaban en la zona, aun cuando se le siguió invocando en el discurso estatal como justificación para la suspensión de garantías constitucionales hasta mediados de 2015. En la medida que el boom de la coca y el conflicto armado de décadas pasadas generaron un espacio de experiencias y horizontes de expectativas de los ciudadanos del Huallaga (Kernaghan, 2009), el significante «estado de emergencia» siguió funcionando como un conector entre el pasado y el presente, creando un escenario de continuidad que afecta una serie de ámbitos de la vida cotidiana, pero en especial a las diferentes versiones locales de lo oficial y con más intensidad en espacios de mayor ruralidad, donde esta experiencia adquiere un mayor peso simbólico. Precisamente es el espacio rural donde la violencia (tanto la política como la derivada del narcotráfico) fue mayor y donde todavía es patente la brecha entre ciudadanía rural y Estado peruano, la cual se intenta cubrir o acortar con dispositivos de gobierno.

En el presente siglo, el Alto Huallaga vivió más de 10 años bajo estado de emergencia, durante tres gobiernos nacionales con la justificación de que la presencia de elementos subversivos constituía un riesgo para la estabilidad. A su vez, estas prórrogas eran dictadas por los sucesivos gobiernos de Alejandro Toledo, Alan García y Ollanta Humala en virtud de informes del sector Interior que daban cuenta de esta presencia subversiva, elaborados sobre la base de dos fuentes, principalmente: la Policía Nacional y las autoridades políticas. No es posible conocer qué pudo haber informado la Policía Nacional en todos esos años, tanto para que se prorrogue como para se deje de prorrogar en el año 2015.

Durante la gestión del presidente Ollanta Humala, en junio del 2015, terminó la vigencia de la última prórroga del estado de emergencia en el Alto Huallaga. Poco después, se desactivaron el Comisionado de Paz y Desarrollo del Huallaga y el Frente Policial Huallaga, ambos dependientes del Ministerio de Interior, al tiempo que los asuntos fueron asumidos paulatinamente por las instituciones regulares, incluyendo las autoridades políticas. El cese del estado de emergencia fue producto de un largo trabajo de cabildeo por parte de las autoridades regionales, municipales y congresistas, acompañados por la Defensoría del Pueblo, con el argumento de que no se justificaban las prórrogas del estado de emergencia porque ya no había actividad de grupos armados y porque esta medida afectaba negativamente la vida social y económica del Alto Huallaga.

Por otra parte, entre los dispositivos gubernamentales que han persistido, a pesar del creciente proceso de descentralización, sobresalen las autoridades políticas (prefectos, subprefectos y tenientes gobernadores) como representantes del poder ejecutivo en sus respectivas circunscripciones territoriales.

La designación de las autoridades políticas es potestad del gobierno nacional, a través de la Oficina 
Nacional de Gobierno Interior, adscrita al Ministerio del Interior. Su función principal es representar al gobierno en la localidad, aunque por tradición y por el sector gubernamental del cual dependen, el énfasis ha estado puesto en los asuntos de seguridad interior y paz social, puesto que le brinda al gobierno la posibilidad de hacer seguimiento cercano a los hechos sociales y políticos de su jurisdicción. En el caso de los prefectos regionales, el vínculo con el gobierno es estrecho pues son designados por el Presidente de la República. Por su parte, los subprefectos provinciales y distritales se relacionan con el gobierno a través de los grupos regionales del partido de gobierno o afines al mismo, siendo usual que estos cargos sean ocupados por simpatizantes o militantes del partido de gobierno en la escala regional.

Sin embargo, esta tendencia encuentra un pronto límite: ningún partido político cuenta con suficientes militantes como para que su gobierno pueda designar como autoridades políticas a ciudadanos que necesariamente se van adherir a la política del Presidente de la República, lo cual se hace más evidente en el caso de los tenientes gobernadores. Ello obliga al gobierno, sea cual fuere su orientación política o ideológica, a adaptarse a los procesos regionales y locales de correlación de fuerzas, aceptando y legitimando liderazgos en cada jurisdicción que en otras circunstancias probablemente no aceptaría.

Cabe notar que los tenientes gobernadores no han merecido un interés significativo desde la academia. Cuando se ha hecho mención a ellos, el énfasis se ha colocado sobre procesos sociales y políticos, dentro de los cuales los tenientes gobernadores cumplirían un papel secundario. En general, el período comprendido entre fines del siglo XX y los primeros ańos del siglo XXI, teniendo presente la experiencia autoritaria y centralizadora del gobierno de Alberto Fujimori, fue el contexto en que empezó a cuestionarse la existencia de los cargos de los tenientes gobernadores, bajo la sospecha de que se trataba de una estructura de poder territorial paralela, sometida al control directo del gobierno central y, por tanto, desfavorable para la descentralización que estaba empezando.

Así, María Isabel Remy presenta a los tenientes gobernadores como «el residuo de regímenes autoritarios en los cuales la autoridad no es electa sino nombrada a dedo por el poder» (2004: 266) y resalta su función de interlocución con los funcionarios de los programas sociales: «si no hay teniente gobernador, no hay intermediario; si no hay intermediario, no hay apoyo» (2004: 267). Remy alerta sobre el hecho de que esta función de intermediación ejercida por los tenientes gobernadores era ya parte del sentido común de la época y corría el riesgo de deslegitimar a las dirigencias comunales, a contrapelo de los avances democratizadores. Esto lleva a la autora a considerar a los tenientes gobernadores como meros representantes del gobierno central, no de la población.

Asimismo, Raúl Santana (2001, citado en Brandt y Franco, 2006: 87), estudiando el caso de comunidades campesinas de Cusco, ubica a los tenientes gobernadores en un conjunto de instituciones tradicionales relacionadas con la gestión local y el uso de los recursos naturales. Con la reforma agraria llevada a cabo por el gobierno militar de Juan Velasco Alvarado, se impulsó una nueva forma de organización para diferentes agendas comunales, los comités (sean de regantes, de productores, pro electrificación, etc.), que subsisten hasta la actualidad. A partir de la década de 1990, en el marco de la lucha contrasubversiva integral llevada a cabo por un régimen centralista, las entidades estatales incrementaron su influencia, afectando el funcionamiento de las instituciones tradicionales.

Por su parte, Damonte (2000: 109-124) expresa un punto de vista que permite valorar de una manera distinta a los tenientes gobernadores. A partir de sus apuntes etnográficos en comunidades rurales andinas cercanas a proyectos mineros en Ancash, Cajamarca, Junín, Cuzco y Apurímac, concluye que la presencia de un teniente gobernador abre la posibilidad de coordinación directa de la comunidad con el Estado y otros actores externos. Así, la representación del teniente gobernador es relevante en la comunidad en la medida que ponga en juego su capacidad de articular y negociar favores para su localidad.

Al respecto, también merece mención el estudio de Ramirez (2017), con tenientes gobernadores del distrito de Chirinos, en Cajamarca, donde, a pesar de los tenientes gobernadores tienen deficiencias sobre sobre el conocimiento de sus funciones, el $62 \%$ de la población manifestaba que los tenientes gobernadores estaban dispuestos a apoyar a los pobres y $8 \mathrm{de}$ cada 10 pobladores percibía que el teniente gobernador solucionaba satisfactoriamente las demandas. 
En ese sentido, resulta razonable inferir que la existencia de los tenientes gobernadores, desde el procedimiento de su propuesta y designación, permite que la voluntad de las comunidades tenga una ventana de oportunidad para expresarse y contar con un representante. De esa manera, estas comunidades (pueblos, caseríos y anexos) tendrían la posibilidad de contar con una autoridad y un interlocutor con el gobierno nacional, sin necesidad de que sea del partido oficialista y obviando instancias de poder distrital y provincial que, eventualmente, podrían no favorecerlas.

La revisión bibliográfica de estudios sobre poder político en ámbitos rurales del Perú, permitió observar la ausencia de investigaciones sobre el trabajo de los tenientes gobernadores no obstante su función de intermediación entre éste y los ciudadanos de agrupamientos poblacionales reducidos y que muchas veces no cuentan con representantes propios elegidos del voto popular. Esta ausencia, motivó la presente investigación teniendo en consideración los conceptos de Sartori de representatividad y representabilidad, así como los fundamentos de la «teoría de la representación responsable», es decir, «que asegure la obligación de responder». (Sartori, 1999: 258). Además, se tomó en consideración lo señalado por Mainwaring (2002) acerca de la problemática de la representatividad originada tanto por la personalización-individualización de la representación como por la distancia entre el individuo representante y el partido que es elegido para el gobierno. El caso del Alto Huallaga se presentaba propicio para el análisis. En él, el fenómeno de la representación adquiere notoriedad en la medida que las prioridades del gobierno se orientaban a la seguridad interior (especialmente, el control de la oferta de drogas derivadas de la coca), mientras que, en la percepción de los tenientes gobernadores, algunas medidas adoptadas por el gobierno central y que afecta directamente diversos ámbitos de la vida cotidiana de la comunidad han sido decididas por agentes externos, incrementando la brecha entre el rol asignado y el rol ejercido como expresión de la distancia entre Estado y comunidad.

Por ello, se consideró la necesidad de observar con mayor detenimiento el trabajo de estos servidores y entenderlo como la articulación entre lo político y lo comunitario y entre lo gubernamental y lo social, siendo más evidente esta función precisamente donde la presencia del Estado es menos sentida: el espacio rural. El trabajo de estas personas constituye un capital social valioso que está al servicio de los fines del Estado para con sus ciudadanos.

En ese sentido, el objetivo fue comprender las prácticas y actitudes relacionadas al ejercicio de la función de representación los tenientes gobernadores con respecto a sus comunidades y al gobierno nacional.

Para alcanzar dicho objetivo, se plantearon las siguientes preguntas de investigación:

¿Qué relación existe entre el proceso de designación de los tenientes gobernadores y la orientación que adopta su desempeño efectivo en el cargo? ¿Qué funciones terminan desempeñando de manera más regular los tenientes gobernadores, tanto con respecto a sus comunidades como con respecto al gobierno? ¿Cómo perciben su labor los tenientes gobernadores y cómo se relacionan con sus comunidades y con el gobierno?

Para responder a estas interrogantes, la investigación estuvo orientada por la hipótesis general de que el proceso de designación de los tenientes gobernadores como autoridades políticas, que incluye la potestad de las comunidades para proponer las personas que desempeñen esta función (donde intervienen elementos de la historia personal y comunitaria), genera las condiciones para que el ejercicio de las tenencias de gobernación (es decir, sus actividades cotidianas y prioridades de gestión) se desarrolle en función de las necesidades y prioridades de las comunidades antes que en la representación del gobierno.

\section{Metodología}

Se empleó una metodología cualitativa, con la entrevista como técnica de recolección de información. Se consideró el universo de tenientes gobernadores de las localidades rurales en toda la provincia de Leoncio Prado. De este universo, se seleccionaron tenientes gobernadores de 16 localidades rurales, tomando en cuenta que debían ser de todos los distritos de la provincia, que sus localidades sean accesibles y que los posibles entrevistados estén dispuestos a narrar sus experiencias, después de dar su consentimiento informado. En el tiempo en que se realizó el estudio, 
entre los ańos 2014 y 2015, el autor trabajó en la coordinación de un proyecto de educación ciudadana en diferentes localidades rurales de la provincia de Leoncio Prado, lo que le permitió conocer el contexto $y$ establecer en contacto con diversas autoridades y líderes locales. A partir de esta relación previa fue posible seleccionar y convocar a los entrevistados, así como recoger información referencial sobre el entorno social, económico y los antecedentes históricos del Alto Huallaga.

Las entrevistas se realizaron sobre la base de una guía en la que se abordaron los siguiente temas: los antecedentes de la vida personal y familiar del entrevistado y sus experiencias previas de liderazgo; el proceso de convertirse en autoridad política; las tareas desempeńadas por teniente gobernador y su relación con el gobierno y la comunidad; así como sus percepciones sobre su comunidad, la democracia y el estado de emergencia.

Las entrevistas se hicieron en las comunidades donde residen los tenientes gobernadores, dentro del tiempo que voluntariamente brindaron a la presente investigación. Cada entrevista fue grabada en audio y posteriormente transcrita.

\section{Resultados}

La realización del trabajo de campo a través de las entrevistas y el posterior análisis ha permitido observar aspectos relevantes sobre el proceso en que determinados ciudadanos de las localidades rurales se convierten en tenientes gobernadores y la manera en que desempeñan su cargo.

Como tendencia dominante, los tenientes gobernadores, antes de ser designados como tales, ya habían ejercido algún cargo de responsabilidad pública. Esta experiencia previa habría dado a la comunidad elementos de juicio suficientes para elegir a estos ciudadanos para que ocupen estos cargos. Así, los tenientes gobernadores habrían tenido que demostrar ante su comunidad que tenían algún tipo de capacidad para hacer las veces de representante.

Los cargos anteriores son de diversa naturaleza: agente municipal, dirigente de junta de regantes, líder escolar, líder cocalero, profesor, dirigente de construcción, incluso teniente gobernador en otra comunidad (o la misma), entre otros. El común de- nominador es que este cargo les pudo dar la posibilidad de interactuar con otros actores e instancias de poder local, regional o nacional, o con representantes de instituciones del estado. De esta manera, ante los ojos de la comunidad, este antecedente organizacional les habría enseñado a relacionarse mejor con estas instancias de poder $y$, de cara al futuro, les habilitaría para representar más eficientemente los intereses de la comunidad frente a estos poderes. Esto se percibe con mayor claridad cuando se da cuenta del procedimiento de elección.

Cuando ya acabé mis estudios, yo ya tenía una parcela grande de coca, entonces en una reunión un grupo de cocaleros me nombraron como directivo debido a que había estudiado, sabía redactar documentos, hablar en público, es por eso que llegué a ese cargo. Aprendí muchas cosas, tuve la oportunidad de salir y bien doy gracias al pueblo que me nombre (EP nro. 3, Pucayacu).

Hace nueve años que tenemos reconocimiento como caserío, desde esa fecha hemos venido trabajando con diversas autoridades yo como teniente gobernador ya es mi segundo periodo y el primero fue el 2007 al año 2009 y esta vez nuevamente fui elegido. [Antes] ocupé el cargo de promotor de salud y luego el cargo de teniente gobernador, también fui tesorero del pueblo (EP nro. 10, Shapajilla)

El proceso por el cual un ciudadano llega a ocupar el cargo de teniente gobernador es relativamente sencillo. En la comunidad se proponen a algunas personas, que son refrendadas por la asamblea y se designa a una terna de tres elegibles que será propuesta a la gobernación distrital. En la asamblea comunal, donde participan los jefes de familia de la comunidad, se vota quién ocupará el cargo de teniente gobernador (el que tiene mayor votación) y de alguaciles (los dos restantes).

Los entrevistados declararon, sin excepción, que fueron propuestos "por la población» dentro de una terna que se planteó en una asamblea comunal. En estas asambleas, "la población» delibera sobre cuál es la mejor opción para que ocupe ese cargo y se pasa a una votación. Cabe indicar, que estas asambleas vienen precedidas por ciertos consensos que se van articulando de casa en casa, de barrio en barrio. Cuando llega el momento de la asamblea, el resultado de la 
elección suele ser el esperado, en la medida que se elige entre una terna de elegibles.

Porque siempre me gusta las cosas serias, siempre me gusta trabajar bastante por mi comunidad y mi familia juntamente con las autoridades es por eso que me gané el cariño del pueblo y por eso me pusieron autoridad. (EP nro. 5, Anda)

Quizás porque yo hablé en la reunión diciendo que las autoridades no hacen prevalecer los derechos de nuestro pueblo, entonces la comunidad me eligió que sea yo teniente gobernador, entonces yo dije «si el pueblo me confía, magnífico, yo recibo el cargo» (EP nro. 6, Angashyacu)

Es importante señalar que en este tipo de asambleas comunales ni la participación ni la votación son universales: no participan y/o no votan todos los ciudadanos y ciudadanas aptos, sino los representantes de cada familia (generalmente varones jefes de familia, a veces acompañados por sus esposas). A pesar de este sesgo, todos los entrevistados daban por sentado que la decisión de esa asamblea expresa la voluntad popular, a falta de otra fuente de legitimación local. Si bien no parece existir alguna norma oficial sobre el perfil ideal de una autoridad política, una revisión de sus funciones permite percibir que se trata de una labor que no requiere una calificación mayor a saber leer, escribir y hacer cálculos simples. Más allá de aptitudes específicas requeridas, el texto de la norma da a entender que el teniente gobernador debe gozar de una legitimidad social donde el reconocimiento por parte de la Oficina Nacional de Gobierno Interior constituye el acto de investidura simbólica. Casi siempre la propuesta de la comunidad era asumida y ratificada por ONAGI, en la medida que no es posible imponer un militante o un simpatizante del gobierno para que ocupe un cargo ad honorem en una comunidad rural. En cambio, los cargos de prefecturas y subprefecturas (cargos remunerados) sí suelen ser ocupados por simpatizantes del gobierno nacional, o al menos se muestran como tales. En las primeras indagaciones, se tuvo la oportunidad de sostener reuniones con autoridades políticas distritales en cuyas oficinas tenían la fotografía del presidente de turno y se referían a sí mismos como integrantes del gobierno.
Cabe señalar que, antes de asumir el cargo, la mayoría de los tenientes gobernadores confió en poder desempeñarlo debido a su experiencia previa - en el mismo cargo o ayudando a otro teniente gobernador- que les habría permitido conocer sus funciones y lo que se espera de ellos fuera de la comunidad. Sin embargo, los más jóvenes no experimentaron esa confianza inicial, por desconocimiento de las funciones, pero con el respaldo de otros miembros de su comunidad, han ido fortalecido sus capacidades progresivamente. La incertidumbre inicial se percibe en perspectiva como un proceso de aprendizaje.

Miedo quizás un poco, sobre todo al inicio, pero al transcurso de los días al ver que la comunidad se encuentra ya casi en el fracaso ya puse de mi parte para aprender y ahora sí ya me desenvuelvo como autoridad. Bueno como yo soy licenciado del ejército, sabía las funciones del ejército pero no sabía las funciones de un teniente gobernador, no sabía en qué consistía. Pero el gobernador distrital nos dio unas capacitaciones y así poco a poco fui aprendiendo para no caer en ningún error. (EP nro. 6, Angashyacu)

Temor no, solo un poco de duda, por el simple hecho que no soy propietario acá y no cuento con movilidad. Las personas que estaban nominados tienen su movilidad y ellos les dijeron que serían los subtenientes, y ellos me preguntaron si aceptaría el cargo, y les respondí que el cargo no mata y el reto está hecho además solo son 2 años y pasan rápido lo único que necesito es el respaldo de ustedes pero solo de vez en cuando y lo demás yo me encargo además siempre he querido llegar a este tramo para ver si todavía tengo ese ánimo que tuve en el colegio como líder de mi sección a ver si puedo conducir un pueblo, aunque es pequeño pero así nacieron los grandes líderes (EP nro. 15, Inkari).

Aunque todos tienen claro que son formalmente representantes del gobierno nacional en su localidad, ninguno refiere que éste haya contribuido en un nivel significativo con su proceso de hacerse autoridad política. Por el contrario, se percibe que su representatividad y autoridad emanan de la comunidad y del deseo de solucionar los problemas.

Representamos a nuestro pueblo porque ellos nos eligen, entonces tenemos que velar por nuestro pueblo porque estamos dentro de él, porque el go- 
bierno ni nos conoce pero mi comunidad sí, por esa razón nosotros siempre tenemos que representar al pueblo. (EP nro. 13, Cayumba)

De manera general, los tenientes gobernadores son conscientes de que la función principal del cargo que ocupan es representar al gobierno en su localidad. En ese sentido, la expresión «llevar la presencia del Estado» da a entender que las instituciones y sus normas no siempre están funcionando en la vida de las comunidades y es preciso hacerlas presentes colocando un representante.

Presencia del Estado es hacer respetar, cumplir las leyes y hacerlas cumplir... Interviene en todos los acto que tiene las instituciones que tiene el estado, por ejemplo si se está haciendo un trabajo en una institución educativa como están haciendo acá en el Colegio Inca Huiracocha nosotros intervenimos para ver qué está ocurriendo y cuando hubo un conato yo he ido a conversar del enfrentamiento entre el sindicato de trabajadores de construcción civil y los ingenieros de la empresa que está construyendo ese colegio... intervenimos, entablamos una conversación, hicimos una mesa de diálogo para solucionar ese problema... entonces para eso es la presencia del Estado, porque yo represento al Presidente de la República acá en Aucayacu. (EP nro. 7, Aucayacu)

Representar al gobierno, sin embargo, puede ser interpretado como representar a la presidencia de la nación, al margen de la persona que ocupe el cargo en determinado período, sin que ello implique necesariamente un compromiso con el gobernante «de turno»

Yo rumbo político nunca lo he manejado como le expliqué antes, la política es otra cosa y la función es otra, yo veo más por el desarrollo y respeto a la política así hemos trabajado con Alan García, ahora estoy con Ollanta y respeto a ambos pero yo me voy al desarrollo de mi pueblo más que el lado político sea cual sea la camiseta... Represento más al pueblo pero también hay que respetar al gobierno y obedecer sus normas y leyes, pero más me pongo la camiseta de mi pueblo. (EP nro. 10, Shapajilla)

Por otra parte, en la medida que se ha ido extendiendo la presencia del gobierno nacional en el espacio rural, a través de la ampliación de la cobertura de los diversos programas sociales (Juntos, Pensión 65, Cuna Más, etc.), económico-productivos (DEVIDA, Agrobanco) y otros (Electrificación rural, COFOPRI, ETC.), requiere del trabajo voluntario de un agente local que tenga, al mismo tiempo, alguna responsabilidad respecto del gobierno y legitimidad respecto de la ciudadanía. Confluyen así, la necesidad del gobierno nacional de llegar al espacio rural más disperso con sus políticas públicas, y el interés de la población de acceder a estos programas para satisfacer alguna necesidad. Esa necesidad de la política nacional configura un escenario en el que el teniente gobernador se convierte así en un apoyo local de los programas del Estado dirigidos a la población pobre y rural.

Nosotros vigilamos los programas sociales, que sean los beneficiarios de acá y que no estén entrando personas fantasmas y toda esa situación. [Los programas llegan] mediante el alcalde (del centro poblado), siempre en coordinación con la Alcaldesa del distrito, sí se estaba viendo, pero esos programas son difundidos por el estado (EP nro. 5, Anda)

Como tenientes gobernadores nuestro trabajo está basado a las leyes, hacerlas cumplir y actuar según lo que dicen las normas, porque somos los representantes del gobierno central en cada caserío, vemos los programas sociales, apoyo al agente municipal en los quehaceres (EP nro. 4, Yacusisa)

Sin embargo, cada uno de estos programas tiene sus propios procedimientos, en los cuales no necesariamente el teniente gobernador tiene una participación relevante.

Acá solo vienen a inscribir, no me avisan incluso ni el alcalde sabe que llegan representantes de tal programa, vienen se instalan e inscriben a cualquier persona cuando lo lógico sería que lleguen y presenten algún documento poniendo de conocimiento a las autoridades para que nosotros podamos verificar a quien se inscribe. Sólo vienen e inscriben a cualquier persona, entonces yo pienso que se debería hacer presente a la autoridad para poder ayudar $y$ ver a qué familia le corresponde verdaderamente tal programa. (EP nro. 3, Pucayacu)

Por ello, aunque en el plano local un programa requiere apoyo de las autoridades para difundir el mismo y validar información de beneficiarios, no siempre se 
realiza este involucramiento, situación que hace que el teniente gobernador se limite a una función de vigilancia posterior a la ejecución local del programa.

Instalados ya en su cargo de tenientes gobernadores, la ciudadanía demanda su intervención en casos que presentan un desafío a sus capacidades personales pero también a la competencia de su función como autoridad política. Así, por ejemplo, los casos de violencia familiar o de derechos de propiedad, en los que el teniente gobernador percibe la urgencia de los demandantes y se siente impelido a dar una solución.

Lo que más existe es la violencia familiar tanto maltrato físico y psicológico muchas veces las personas son los varones que es estado etílico maltratan a su pareja. En estos casos, la señora pone su denuncia. Se llama a su pareja y se le orienta de cómo deben comportarse tanto el varón como la mujer, si la persona sigue en el mismo error mi persona ya da pase al Juez de Paz y él ya decide (EP nro. 3, Pucayacu).

En realidad como le digo nosotros hacemos las veces de jueces, hacemos las funciones del mismo gobernador, representamos al gobierno central al Ministerio del Interior, hacemos muchas cosas y somos multifuncionales (EP nro. 15, Inkari)

Intervengo, por ejemplo, en pleitos, violaciones... también tengo cuatro proyectos acá: el colegio inicial, el hospital, otro inicial y la casa de reposo de la madre gestante, pero como hay controversias no se puede avanzar pero al menos saqué las constancias de posesión, los planos, todo eso por mi gestión (EP nro. 16, Supte San Jorge)

También hay casos en los que se atiende la demanda a través de la aplicación directa del reglamento

Como teniente gobernador recepciono (sic) denuncias... si está en mi competencia trato de solucionar si el problema es grave lo que hago es enviar a mi superior puede ser a la gobernación o al Juez de Paz. También a veces vienen documentos para notificar del Poder Judicial la Fiscalía lo que hago es buscar a las personas y hacer llegar la notificaciones. (EP nro. 13, Cayumba)

Los tenientes gobernadores no reciben una remuneración, tampoco reciben recursos necesarios para desempeñar sus funciones, ya se trate de insumos o mobiliario; los trámites que tuvieren que realizar les significan un gasto personal. Esto dificulta su trabajo $\mathrm{y}$, a veces, paraliza las acciones

Lo que sí me dificulta es que a veces tengo que informar y a veces no se puede por primero que no ganamos sueldo y no tenemos dinero suficiente porque cuando informamos tenemos que llevar los documentos hasta Tingo María y el pasaje es caro ida y vuelta son 8 soles más tu comida o a veces si tenemos que mandar con una empresa de transportes también tiene un costo entonces por esa razón no informo y eso el gobernador tiene conocimiento (EP nro. 11, Bolaina).

Yo no soy propietario ni tampoco tengo movilidad entonces deberían darnos ese incentivo (EP nro. 15, Inkari)

El estado no nos brinda ningún apoyo, no nos paga ningún sueldo pero a pesar que nosotros representamos al estado dentro del caserío no recibimos nada (EP nro. 12, Naranjillo)

En algunas ocasiones, recurren al cobro a los interesados para la obtención de un documento o solicitan dinero para movilizarse con el fin de realizar alguna gestión

No recibimos ninguna remuneración, son cargos ad honorem por querer enseñar a nuestra comunidad y poner algunas cosas en orden, solo trabajamos con pequeños recurso de la comunidad. (EP nro. 4, Yacusisa)

Hacemos algunos documentos y cobramos por ello como constancias, permisos para movilizarnos sacamos plata del pueblo lo que se logra con las actividades pero todo damos a conocer previo recibo en que se gastó el dinero. (EP nro. 10, Shapajilla) Si hablamos de la caja chica estamos facultados a dar constancia domiciliarias y lo hacemos a un costo módico de 10 nuevos soles con eso ya compramos papel bond archivadores y también para movilizarse cuando salgo al campo hay que echar 20 soles de gasolina... a la semana se expide entre 1 a 3 constancias, hoy se expide constancia pero son para programas sociales pero eso solo son de apoyo en ese sentido no hay ingreso (EP nro. 12, Naranjillo)

En la medida de sus posibilidades, los vecinos aceptaban realizar estos pagos, con la expectativa de solucio- 
nar pronto sus asuntos. $\mathrm{Al}$ margen de que la inclusión del dinero haya favorecido o no a alguna persona de manera irregular o ilegal, estos pagos podrían distorsionar la relación entre las autoridades políticas y los ciudadanos, al convertirla en una de tipo transaccional antes que una de servicio público. Hubo casos en los que, al no conseguir recursos en la comunidad, se buscaban otras opciones (por ejemplo, usar los recursos propios), lo cual llevaba a cuestionar las relaciones entre el gobierno nacional y las comunidades, más allá de los asuntos de gobierno interior.

Yo a veces con mis propios recursos, ya que no tengo ningún recurso económico de parte de nadie ni siquiera mi comunidad cuenta con recursos, como esta zona han erradicado la coca ya no tienen recursos para solventarse hay familias que están yendo por la sierra y otras se están desplazando a otros lugares por el motivo que no tienen economía porque el cacao y las alternativas que prometen no llegan vienen los ingenieros incluso nos hacen firmas actas y luego desaparecen y no vuelves nunca más (EP nro. 6, Angashyacu)

De otro lado, también hay demandas que exigen movilizar recursos más bien relacionados con el capital simbólico que puede tener el teniente gobernador. Después de todo, se trata de una autoridad que ha sido propuesta y reconocida por una asamblea comunal y los tenientes gobernadores utilizan su posición para buscar que la maquinaria estatal atienda las necesidades de la comunidad.

En este caserío la mayor parte de casos son de maltrato familiar, entre ellos también maltrato psicológico, y algunos problemas que se presentan entre vecinos... Bueno nosotros en las reuniones invocamos a las personas a vivir tranquilos, ahora la manera de intervenir en estos casos es llamando a las partes, para conversar y educarlos (EP nro. 16, Supte San Jorge).

Estoy pensando en gestionar para hacer una posta médica o un puesto satelital para que llegue un pan para esos nińos... Quiero empezar esa gestión de por lo menos hacer un puesto satelital, para que llegue el seguro y atiendan a los niños de los caseríos más lejanos y se atiendan ahí, porque a veces por falta de recursos económicos no salen a atenderse. Hay algunos niños que no tienen partida de nacimiento, no tienen control médico y los ancianos se mueren en las chacras y lo entierran como si fuera un animal, los anciano son tiene seguro y yo he visto con mis propios ojos (EP nro. 6, Angashyacu).

En ese sentido, se percibe que el ejercicio concreto de las tenencias de gobernación constituye una manera de desarrollar la representabilidad de estas comunidades, es decir, de la capacidad y posibilidades de los ciudadanos de establecer demandas organizadas ante el poder. No la única, ciertamente, pero sí una que es accesible y disponible en la localidad. Otros aspectos que también resaltaron en las entrevistas fueron sus percepciones sobre la democracia y el estado de emergencia entonces vigente. Desde la perspectiva de los tenientes gobernadores, la democracia peruana se caracterizaría por su conflictividad, burocracia y escasa representatividad.

Para mí el Perú no es tan democrático, porque siempre hay rivalidades en funcionarios públicos, pero acá en mi pueblo sí estamos en un $70 \%$ de democracia porque vivimos de manera pacífica, y estamos más tranquilos porque lo del partido comunista ya está bajando y es más tranquilo, ya no como los años anteriores (EP nro. 3, Pucayacu)

[Si hubiera democracia] así sería bonito, pero estamos representado por poderes ya que los padres de la patria toman las decisiones por nosotros porque muchas veces no estamos de acuerdo pero como son leyes hay que cumplirlos, (EP nro. 8, Los Milagros).

También se relaciona el déficit de democracia con la estigmatización derivada del conflicto armado

[El país] no es democrático al cien por ciento, en la parte política por ejemplo se ve mucha burocracia, por ejemplo nace un partido político y si participas ahí ya te culpan y satanizan diciendo que perteneces al Movadef, anteriormente te incluían en lo que es Sendero y narcotráfico haciéndote descalificar de la sociedad, se te escapa la confianza de la población, además pues a los corruptos se les trata de tapar con alguien que es inocente haciéndolo salir del camino y al final el que no es santo se queda ahí y eso dificulta el desarrollo de la democracia (EP nro. 15, Inkari). 
Por otro lado, en las comunidades el ejercicio de la democracia se caracterizaría por el debate, la participación y la persuasión, en lugar de la imposición.

[En mi pueblo hay democracia] porque siempre cuando queremos hacer algo nos reunimos las autoridades, intercambiamos ideas que luego llevamos a la asamblea y ahí se decide lo que se hace, si no sería democrático todas las cosas serían impuestas (EP nro. 13, Cayumba)

Democráticamente sí estamos avanzando, en la libertad de expresión, voto popular... sí estamos avanzando en democracia (EP nro. 10, Shapajilla).

Esta percepción muestra un escenario que contrasta con el pasado de violencia política de la región, el cual todavía seguía siendo parte del marco de referencia para percibir la realidad. En este caso el rasgo distintivo apunta a relacionar la democracia local con una situación de paz o, al menos, posterior al conflicto.

Como se sabe por parte del gobierno no había tanta democracia porque todos vivíamos cohibidos por la cuestión política que existía en este lugar, más que todo este lugar ha sido completamente golpeado por la subversión y no se puede decir que había tanta democracia. Ahora sí ha cambiado bastante, se está haciendo caso a los actos del gobierno (EP nro. 5, Anda).

Creo que sí porque el gobierno está llegando hasta las partes más lejanas yo creo que sí vivimos en un país democrático, ya se acabó la dictadura ahora ya tenemos más paz y más aún con la caída del señor Artemio. (EP nro. 4, Yacusisa)

Los tenientes gobernadores percibían el impacto negativo del estado de emergencia para que los ciudadanos puedan vivir en paz y desarrollarse. En este caso, el estado de emergencia sería un elemento relacionado con un pasado ya superado, pero cuya actualización periódica (en ese tiempo) era un obstáculo para pensar un futuro diferente.

(Debería levantarse) para que no haya abuso de parte de la policía y esté cargando personas inocentes. Dicen que son de Sendero Luminoso y los llevan pero muchas veces no son pues tal vez la gente ha sido porque los obligaban a que sirvan a ese grupo. (EP nro. 2, San Isidro)
En el Alto Huallaga sí, porque el estado de emergencia nos prohíbe reclamar nuestros derechos, en sí el Alto Huallaga está olvidado no es como el VRAEM donde va cantidad de dinero para que puedan apoyar la zona agrícola, zona comercial, pero acá no hay nada de eso, eso creo que dificultado el estado de emergencia. (EP nro. 4, Yacusisa)

Por otro lado, hay una posición que cuestiona al estado de emergencia por su desempeño deficiente para garantizar la seguridad ciudadana

Yo creo que se debería estar en estado de emergencia, pero el estado debería hacerlo bien tanto apoyando en la seguridad ciudadana, la policía debería estar continuamente rondando ya que muchas veces cuando hay por ejemplo un robo se llama a la policía y nunca te hacen caso. A veces, cuando muere una persona llamas al comisario y no te hacen caso, como estamos en estado de emergencia deberíamos de recibir más apoyo de parte de ellos ya que eso es su trabajo y deberían venir al pueblo para brindar mayor seguridad a la población (EP nro. 3, Pucayacu)

Asimismo, el estado de emergencia se justificaría si se aplica a la población de mayor ruralidad, por su supuesta relación con la violencia.

Diría que sí (se justifica el estado de emergencia) sobre todo por los demás caseríos más alejados ya que han tenido un pasado bastante movido en el tema de la violencia política ya que todavía se dice que hay rezagos, quizás por prevención a eso puede ser factible (EP nro. 15, Inkari).

Son rezagos quizás de la gente de Artemio y otros grupos. Por ejemplo, mucho de los dirigentes cocaleros han sido aliados de Artemio y ellos inclusive están denunciados, están procesados, de todas maneras hay todavía coca en el Huallaga por ejemplo en el Monzón tenemos coca, que pasaría si el gobierno anula el estado de emergencia para ellos sería más fácil hacer prevalecer lo ilegal entonces yo creo que primero se tiene que erradicar toda la coca ilegal (EP nro. 14, Las Palmas)

Finalmente, desde esta perspectiva, el estado de emergencia ha funcionado como un "mal necesario», un elemento de la realidad que aunque no era beneficioso, su ausencia habría sido percibida como más grave, vinculada al pasado de violencia y auge del narcotráfico. 
Los tenientes gobernadores reconocían que ellos no participaban en ninguna etapa de la decisión de prorrogar el estado de emergencia. Aunque era una medida que los afectaba directamente en diversos ámbitos de la vida cotidiana, era un elemento totalmente ajeno y decidido por los especialistas del gobierno en la capital, tal como ellos lo reconocían

No nos da información que es el estado de emergencia ni cómo actuar en este caso (EP nro. 4, Yacusisa)

No me puedo meter en eso ya que ellos son los que manejan la investigación a nivel nacional con los especialistas, con técnicos, entonces no es fácil dar mi opinión yo solo le hablo de mi zona no de lo demás si los técnicos dicen que si entonces que continúe (EP nro. 15, Inkari).

\section{Discusión}

La separación entre las prácticas de representar a la comunidad y representar al gobierno sugiere la necesidad de establecer un diálogo entre los resultados y la noción misma de representación. Por un, lado ejemplifican la problemática de la representatividad (Mainwaring, 2002) que se deriva de la personalización-individualización de la representación y profundizada por la distancia entre el individuo representante y el partido de gobierno, asociado con la crisis de partidos y del sistema de partidos que se expresa en la dificultad de los actores políticos de plantear ofertas que respondan a reales demandas de la población. Otro aspecto de la representación es la cuestión de la representabilidad, es decir, la capacidad y posibilidades de los ciudadanos de establecer demandas organizadas ante el poder. Al respecto, Sinesio López (2009) identifica cuatro elementos relacionados a la desigualdad que constituyen obstáculos para la representabilidad: a) Acceso efectivo diferenciado a los derechos reconocidos por el Estado, que hace que los ciudadanos menos favorecidos (generalmente, personas que viven en áreas rurales de la sierra y la selva) sólo ejerzan sus derechos políticos, accedan a pocos derechos civiles y sociales y no tienen representación política formal; b) configuración desequilibrada de la ciudadanía, según la cual ésta es más política que civil y social.
Sin embargo, en la medida que la mayoría de ciudadanos no goza de plenas libertades civiles ni de las condiciones para ejercerlas, es poco probable que la representación pueda ser ejercida con calidad; c) las élites y los gobiernos tradicionalmente han excluido de la representación a la mayoría de la población que no es criolla ni occidental, impidiendo su integración y el reconocimiento de sus diferencias culturales; y, d) desigualdad ante la ley, puesta de manifiesto en el hecho de que la inmensa mayoría encuentra excluida del acceso a la justicia. Sin embargo, estas dificultades no limitan el interés de los ciudadanos de las localidades rurales por expresar sus demandas al gobierno y colocarlas en el espacio público, utilizando incluso canales institucionales de maneras poco o nada convencionales para obtener alguna forma de representación. La noción de representación aplicada a las autoridades políticas permite una aproximación a la naturaleza y funcionamiento de los tenientes gobernadores, incluso en la medida en que el proceso por el que estos ciudadanos llegan a ocupar estos cargos, se mantienen en ellos y se retiran de los mismos, tiene un amplio margen de indeterminación e, incluso, informalidad. A primera vista, la autoridad de los tenientes gobernadores se relacionaría con las formas de representación política y jurídica. Sin embargo, en su origen se encuentra la representación sociológica, como una marca de nacimiento, aportando legitimidad pero también generando condiciones para situaciones complejas.

Hasta ese punto, es posible reconocer y entender las condiciones en que los tenientes gobernadores desempeñan sus cargos como representantes, al mismo tiempo, del estado, del gobierno y de sus comunidades. Abordar el tema de la representación, «volver a presentar algo", $\mathrm{y}$ "hacer presente a algo o alguien que no está presente», conduce a considerarlo tanto en la dimensión de proceso como de producto. En tanto producto implica que «unos signos hagan las veces de sus sentidos». Noción útil por cuanto unifica lo que a simple vista puede parecer un conjunto de fragmentos conceptuales. En tanto proceso se trata de poner «en formas concretas (es decir, diferentes significantes) un concepto abstracto». La representación es así «un proceso social de significar», que en su connotación política "corresponde al uso que se da en la retórica parlamentaria en la que los líderes profesionalizados 
actúan socialmente en favor de otros a los que se supone que representan» (Hartley, 1995: 307).

Así, trasladada al ámbito de la representación política, la noción adquiere mayor complejidad implicando que determinados miembros de las colectividades, actúen en representación del conjunto, tomen decisiones sobre la vida común y la forma de gobernar a los sujetos del mundo social.

En todas las normas respecto a los tenientes gobernadores (Ley 30057, 2013; Ley 30438, 2016) se refieren a ellos como "autoridades políticas». Es ahí donde también es necesario profundizar. Si bien la legitimidad social de los tenientes gobernadores puede emanar indirectamente de una elección en una asamblea comunal, es indispensable tomar en cuenta que esta elección no es vinculante ni forma parte de los procesos institucionalizados del gobierno. La investidura política, su carácter de autoridad, es conferida por el gobierno, pero ¿qué poder es exactamente el que reciben los tenientes gobernadores para ejercer en sus comunidades? Desde la perspectiva de un gobierno nacional, el teniente gobernador sirve como un canal de intermediación, una manera práctica de relacionarse con los ciudadanos, extendiendo la aplicación de las políticas nacionales de gobierno, sin necesidad de movilizar recursos humanos especializados y con legitimidad social. Históricamente, las relaciones entre el gobierno peruano y las comunidades rurales han tenido de las tres formas de relación: ha habido intentos de imposición de políticas de estado por parte de los gobiernos, especialmente en temas de seguridad interior y promoción de las inversiones; ha habido también resistencia por parte de las comunidades y, por consiguiente, conflicto; pero además han habido espacios y canales para que tanto el gobierno como las comunidades actúen con una cierta racionalidad instrumental para lograr sus fines, sea resolviendo los conflictos o dejando situaciones abiertas.

\section{Conclusiones}

El presente estudio permite confirmar que los tenientes gobernadores son elegidos como tales en asamblea comunal y la Oficina Nacional de Gobierno Interior ratifica tal elección. Sin embargo, antes de la realización de la asamblea, dentro de cada comunidad hay consenso sobre los criterios para elegir a la próxima autoridad política: debe tener experiencias previas en el mismo cargo, o en cargos donde se haya puesto en juego su capacidad para ejercer liderazgo; debe tener relaciones con otros actores, es decir, se valora positivamente la amplitud de redes sociales que una potencial autoridad política tenga a su disposición, especialmente si esas redes llegan al gobierno regional o nacional; y, debe tener habilidades comunicacionales, como el saber escribir cartas u oficios, o tener fluidez verbal, que son valorados por la comunidad en tanto se considera que estas habilidades permiten poner en la agenda de instancias de decisión la solución de demandas a problemas comunales.

Respecto a la relación con el gobierno nacional, se constata que el gobierno encarga a los tenientes gobernadores funciones de apoyo a la implementación de políticas sociales. Sin embargo, los programas que ejecutan estas políticas tienen su propios recursos humanos (remunerados, capacitados y bajo su control directo) y procedimientos, lo que limita el involucramiento del teniente gobernador a realizar sólo una tarea de difusión y validación de información de los beneficiarios.

Con relación a la percepción como representantes y líderes de sus localidades, se observa que los tenientes gobernadores, como representantes del gobierno, tienden a verse limitados a participar sólo en actos protocolares (desfiles o juras de bandera, por ejemplo) y a la expedición de constancias necesarias para que los ciudadanos accedan a programas sociales. Sin embargo, realizan acciones que exceden sus funciones como representantes del gobierno, como por ejemplo, interceder ante instituciones para lograr alguna obra de infraestructura importante para el pueblo o la inclusión en su localidad de algún programa social. Ese esfuerzo adicional expresa una tendencia a orientar el ejercicio de la tenencia de gobernación a la atención de necesidades de la comunidad.

El hecho de que la comunidad tenga la posibilidad de proponer al representante del gobierno a nivel local, abre la posibilidad de generar un representante social. Aun cuando la localidad cuente con otros representantes elegidos (como alcalde del centro poblado, por ejemplo), se considera una ventaja contar con otro representante frente al gobierno.

Los tenientes gobernadores desempeñan su función de representación social de su comunidad sobre 
la base de principios de legitimidad. Por una parte, con legitimidad de origen, en tanto son elegidos y proclamados en asamblea comunal, de acuerdo a los usos y costumbres locales. También tienen legitimidad de desempeño, en tanto su trabajo de gestión en favor de su comunidad y la rendición de cuentas generan una percepción positiva dentro de la misma. Adicionalmente, un teniente gobernador es un servidor público con limitaciones y carencias similares a las del resto de los miembros de su comunidad. El gobierno no otorga a los tenientes gobernadores recursos ni incentivos para su trabajo, aun cuando le exija que cumpla su función.

Por otra parte, es significativo el hecho de que aun cuando hay tenientes gobernadores que hacen cobros irregulares por expedir o tramitar constancias, los vecinos asumen la situación como un hecho inevitable debido a la cadena de incumplimientos que proviene desde el gobierno central y que dificulta el trabajo voluntario de la autoridad política local.

Como se indica líneas arriba, las entrevistas fueron hechas cuando todavía estaba vigente el estado de emergencia, lo que hizo posible también tocar este tema y otros relacionados. Los antecedentes históricos de violencia y narcotráfico que ha vivido la región brindan el marco de referencia dentro del cual los tenientes gobernadores interpretan el estado de emergencia y lo vinculaban con las necesidades presentes de sus localidades. El estado de emergencia era percibido como el producto de una decisión tomada por especialistas de la capital, sin participación de ellos, y que afecta la vida cotidiana de las comunidades. Sin embargo, asumían el estado de emergencia como posibilidad para solucionar problemas de inseguridad ciudadana, a pesar de reconocer que la suspensión de garantías constitucionales afecta la vida cotidiana de sus comunidades.

Con relación a la democracia, en la perspectiva de los tenientes gobernadores, la democracia es más accesible en el espacio local que en la escala nacional, y está íntimamente relacionada a la paz y la participación. Esta percepción es importante y debe ser vista en relación con el hecho de que los tenientes gobernadores asumen que su labor obedece a una lógica de participación y representación comunitaria orientada a favorecer la convivencia social y que la presencia del Estado garantice el ejercicio de la ciudadanía.
Lejos de la visión predominante sobre las zonas cocaleras como la de una sociedad «desviada" (Arroyo, 2012), proclive al delito y/o refractaria al poder, la práctica de los tenientes gobernadores en las comunidades rurales, materia de la presente investigación, indica una demanda de representación, un deseo de inscribirse dentro del relato oficial del Estado peruano y de que ese proceso produzca cambios positivos para las personas.

\section{Referencias bibliográficas}

Aramburú, Carlos Eduardo (1984). "Problemática social en las colonizaciones de la selva alta peruana”. En: Centro de Investigación y Promoción Amazónica: Población y colonización en la Alta Amazonía Peruana. Lima: CIPA.

Arroyo, Juan (2012). La sociedad desviada. Cultura y trasgresión en los valles cocaleros del Perú. Lima: Proyecta Lab SAC.

Brandt, Hans-Jürgen y Franco Valdivia, Rocío (2006). El tratamiento de conflictos. un estudio de actas en 133 comunidades de Perú y Ecuador. Serie: Justicia comunitaria en los Andes: Perú y Ecuador. Lima: Instituto de Defensa Legal.

Camino, Alejandro (1984). «La colonización como problemática social». En: Centro de Investigación y Promoción Amazónica: Población y colonización en la Alta Amazonía Peruana. Lima: CIPA.

Damonte, Gerardo (2000). «Apuntes sobre el teniente gobernador». En: Ansión, Juan; Diez Hurtado, Alejandro; Mujica, Luis. Autoridades en espacio locales: una mirada desde la antropología. Lima: PUCP. p.109-124.

Hartley, John (1995). «Representación». En O’Sullivan, Tim y otros. Conceptos clave en comunicación y estudios culturales. Buenos Aires: Amorrortu editores.

Kernaghan, Richard (2009). Coca's gone. Of might and right in the Huallaga post-boom. Stanford: Stanford University Press.

Lesevic, Bruno (1984). «Dinámica demográfica y colonización en la selva alta peruana: 1940-1981». En: Centro de Investigación y Promoción Amazónica: Población y colonización en la Alta Amazonía Peruana. Lima: CIPA.

Ley 30057, Ley del Servicio Civil. Diario Oficial El Peruano, Lima, Perú, 4 de julio del 2013.

Ley 30438, Ley que modifica el Decreto Legislativo 1140, Decreto Legislativo que crea la Oficina Nacional de 
Gobierno Interior. Diario Oficial El Peruano, Lima, Perú, 25 de mayo del 2016.

López, Sinesio (2009). La representabilidad. El zorro de abajo, Blog de Sinesio López Jiménez. En línea: http:// blog.pucp.edu.pe/blog/sinesio/2009/09/17/la-representabilidad (Recuperado el 28. 07. 2014)

Mainwaring, Scott (comp.). (2002). Presidencialismo y democracia en América Latina Buenos Aires: Paidós.

Namuche, Jorge (1995). Historia de Tingo María. Tingo María: Jorge Namuche Rodríguez.

Oficina de Naciones Unidas contra la Droga y el Delito (2018). Perú: Monitoreo de cultivos de coca 2017. Lima: UNODC.
Páucar Mariluz, Felipe (2006). La guerra oculta en el Huallaga, Monzón y Aguaytía. Tingo María: Centro de Estudios y Promoción para el Desarrollo Agroindustrial.

Ramírez Larreategui, Hugo (2017). Programa de capacitación en competencias funcionales para mejorar la calidad de servicio en los tenientes gobernadores del distrito de Chirinos - provincia San Ignacio - 2016 (Tesis de maestría). Universidad César Vallejo, Lima, Perú.

Remy, María Isabel (2004). «Autoridad, gobierno y ciudadanía. Sociedades rurales en democracia». En: El problema agrario en debate. Sepia X/Seminario Permanente de Investigación Agraria. Lima, 2004, pp. 265-267.

SARTORI, Giovanni (1999). «Representación». En: Sartori, G. Elementos de teoría politica. Buenos Aires: Alianza Editorial. 